Provided for non-commercial research and education use. Not for reproduction, distribution or commercial use.

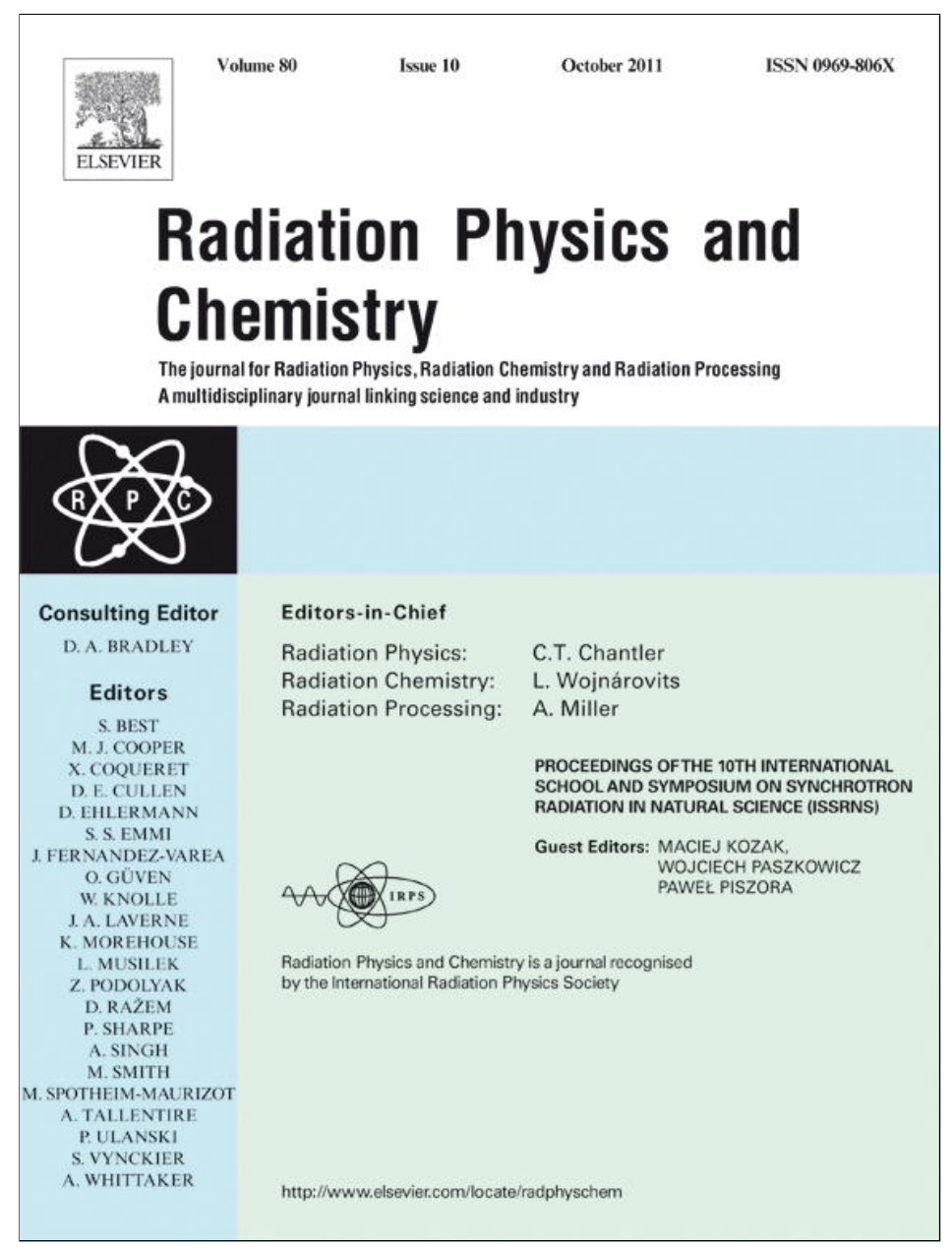

This article appeared in a journal published by Elsevier. The attached copy is furnished to the author for internal non-commercial research and education use, including for instruction at the authors institution and sharing with colleagues.

Other uses, including reproduction and distribution, or selling or licensing copies, or posting to personal, institutional or third party websites are prohibited.

In most cases authors are permitted to post their version of the article (e.g. in Word or Tex form) to their personal website or institutional repository. Authors requiring further information regarding Elsevier's archiving and manuscript policies are encouraged to visit:

http://www.elsevier.com/copyright 


\title{
Distribution of selected elements in atherosclerotic plaques of apoE/LDLR-double knockout mice subjected to dietary and pharmacological treatments
}

\author{
Mariusz Gajda a,*, Joanna Kowalska ${ }^{\mathrm{b}}$, Agnieszka Banaśc ${ }^{\mathrm{c}}$, Krzysztof Banaśs ${ }^{\mathrm{c}}$, Wojciech M. Kwiatek ${ }^{\mathrm{b}}$, \\ Renata B. Kostogrys ${ }^{\mathrm{d}}$, Łukasz Mateuszuk $^{\mathrm{e}}$, Stefan Chłopicki ${ }^{\mathrm{e}}$, Jan A. Litwin ${ }^{\mathrm{a}}$, Karen Appel ${ }^{\mathrm{f}}$ \\ a Department of Histology, Jagiellonian University Medical College, Kopernika 7, 31-034 Kraków, Poland \\ ${ }^{\mathrm{b}}$ Institute of Nuclear Physics, Radzikowskiego 152, 31-342 Kraków, Poland \\ c Singapore Synchrotron Light Source, National University of Singapore, 5 Research Link, 117603 Singapore, Singapore \\ d Department of Human Nutrition, Agricultural University of Kraków, Balicka 122, 30-149, Kraków, Poland \\ e Department of Experimental Pharmacology, Jagiellonian University Medical College, Kopernika 7, 31-531 Kraków, Poland \\ ${ }^{\mathrm{f}}$ Hasylab, DESY, Notkestraße 85, D-22607, Hamburg, Germany
}

\section{A R T I C L E I N F O}

\section{Article history:}

Received 17 August 2010

Accepted 15 February 2011

Available online 22 February 2011

Keywords:

Atherosclerosis

Iron

Zinc

Copper

Calcium

Mouse

\begin{abstract}
A B S T R A T
Gene-targeted, apolipoprotein E and LDL receptor-double knockout (apoE/LDLR ${ }^{-I^{-}}$) mice represent a new animal model that displays severe hyperlipidemia and atherosclerosis. The aim of the present study was to show changes in histomorphology and in distribution of selected elements in atherosclerotic plaques of apoE/LDLR ${ }^{-1-}$ mice fed egg-rich proatherosclerotic diet (5\% egg-yolk lyophilisate) supplemented or not with perindopril (inhibitor of angiotensin converting enzyme; $2 \mathrm{mg} / \mathrm{kg}$ b.w.). Synchrotron radiation micro-X-ray fluorescence spectrometry was combined with histological stainings to determine distribution and concentration of trace and essential elements in atherosclerotic lesions. More advanced atherosclerotic lesions expressed by total area occupied by lipids (oil red-O staining) and by macrophages (CD68 immunohistochemistry) were observed in animals fed egg-rich diet. The perindopril treatment attenuated these effects. No significant differences were observed in the number of intimal smooth muscle cells (smooth muscle actin immunohistochemistry). In animals fed egg-rich diet significantly higher concentrations of $\mathrm{Ca}$ and significantly lower contents of $\mathrm{S}, \mathrm{Cl}, \mathrm{Fe}, \mathrm{Cu}$, $\mathrm{Zn}$ and $\mathrm{Se}$ in atheromas were seen in comparison to chow diet-fed animals. After pharmacological treatment, concentrations of $\mathrm{S}, \mathrm{Cl}, \mathrm{Fe}, \mathrm{Cu}, \mathrm{Zn}$ and Se showed the tendency to achieve levels like in animals fed normal diet. K level differed only in group treated with perindopril. Concentration of $\mathrm{P}$ did not significantly vary in all experimental groups. Perindopril showed its potency to reduce atherosclerosis, as estimated by the size of the atheroma and content of pro- and antiatherogenic elements. (c) 2011 Elsevier Ltd. All rights reserved.
\end{abstract}

\section{Introduction}

Atherosclerosis is a multietiological inflammatory and degenerative vascular disease with growing incidence in westernized populations. It affects large and medium-sized arteries, and the pathology involves endothelial dysfunction, deposition of low density lipoproteins (LDL), migration of inflammatory cells (mostly macrophages) and smooth muscle cells. Oxidation of LDL molecules was proved to be a crucial event in plaque formation. Thickening of vessel wall results from accumulation of lipids (including cholesterol), cells (macrophages and smooth muscle cells), components of extracellular matrix and minerals within the intima (Hansson, 2005).

\footnotetext{
* Corresponding author.

E-mail address: mmgajda@cyf-kr.edu.pl (M. Gajda).
}

Pathomechanism and treatment of atherosclerosis have been extensively studied on animal models for the last decades. Gene-targeted, apolipoprotein E and LDL receptor-double knockout (apoE/LDLR ${ }^{-1-}$ ) mice represent a reliable animal model that displays severe hyperlipidemia and atherosclerosis. We have successively used apoE/LDLR ${ }^{-1-}$ mice to study biological effects of new antiatherosclerotic drugs and diets (Franczyk-Zarow et al., 2008; Jawien et al., 2006). Furthermore, we applied synchrotron radiation microprobes to characterize elemental composition of atherosclerotic lesions in this animal model (Gajda et al., 2008).

Development of atherosclerosis highly depends on nutritional habits. High-fat/high-cholesterol diets strongly promote creation of atherosclerotic plaques in arteries of humans and other species (McNamara, 2000). Egg-rich diets have been reported to accelerate atherosclerosis mostly due to their effect on the serum cholesterol level (Constant, 2004). We found that functional diet with conjugated linoleic acid (CLA-supplemented and CLA-enriched eggs) reduced the 
size of atherosclerotic plaques and lowered the number of macrophages in aortic roots of apoE/LDLR ${ }^{-1-}$ mice comparing to animals fed CLA-free eggs (Franczyk-Zarow et al., 2008).

Besides agents reducing triglyceride and cholesterol levels (e.g. fibrates and statins), other drugs showed potency to reduce atherosclerosis. Perindopril, being a member of angiotensin converting enzyme (ACE) inhibitors, was shown to attenuate the atherosclerosis in mice and in humans (Candido et al., 2002; Ceconi et al., 2009). Recent data suggest that the effects of ACE inhibitors on endothelium may be relevant to attenuate the progression of atherosclerosis.

The role of several trace elements in the development of atherosclerosis was emphasized in the current literature. Some of the elements have proatherogenic properties, mostly due to their ability to oxidize biomolecules. Such effects were observed for iron and copper (Minqin et al., 2005; Lynch and Frei, 1995). Zinc, on the other hand, was shown to reduce development of atherosclerosis (Ren et al., 2006). Increased levels of calcium and phosphorus are indicative for more advanced lesions.

Using histological staining methods some distinct areas of atherosclerotic lesions may be recognized. Atheromas are regions of plaques containing condensed lipid core and numerous macrophages (foam cells). Smooth muscle cells are present not only in their regular location in the vascular media but also in neointima (pathologic musculature that migrated from the media and is mainly present close to the vascular lumen). In some locations, most frequently seen on the border between intima and media and in atheromas, numerous mineral concretions are deposited (Rattazzi et al., 2005).

The aim of the present study was to show changes in advancement of atherosclerotic lesions in aortic roots and in the distribution of selected elements in atheromas of apoE/LDLR ${ }^{-1-}$ mice fed egg-rich diet supplemented or not with perindopril. We have combined synchrotron radiation micro-XRF spectrometry with histological stainings to determine distribution and concentration of trace and essential elements in histologically identified atheromas.

\section{Experimental}

\subsection{Animals and treatment}

Fifteen female apoE ${ }^{-/-} / \mathrm{LDLR}^{-1-}$ mice on the mixed C57BL/6J $\times$ 129/SvJ background were obtained from Taconic (Ejby, Denmark). Mice were kept on $12 \mathrm{~h} / 12 \mathrm{~h}$ light/dark cycle in air-conditioned rooms $\left(22.5 \pm 0.5{ }^{\circ} \mathrm{C}\right.$ and $50 \pm 5 \%$ humidity) and they had access to water ad libitum. Up to the age of 4 months, the animals were fed a commercial, cholesterol-free pelleted diet and then they were randomly assigned to one of three experimental groups fed for the following 2 months: (i) AIN-93G diet (cholesterol-free normal diet background, $n=5$; CHOW; detailed composition in Franczyk-Zarow et al. (2008)), (ii) AIN-93G diet supplemented with 5\% egg-yolk lyophilisate ( $n=5$; LYOPH) and (iii) AIN-93G diet supplemented with egg-yolk lyophilisate and perindopril ( $2 \mathrm{mg} / \mathrm{kg}$ b.w., $n=5$; LYOPH/ PERIND). Six-months-old mice were sacrificed by intraperitoneal injection of sodium thiopental (Morbital, Biowet, Puławy, Poland; $100 \mathrm{mg} / \mathrm{kg}$ b.w.). National and international principles of laboratory animal care were followed and all procedures were approved by Jagiellonian University Animal Experimentation Ethics Committee.

\subsection{Specimen preparation}

In anesthetized mice, thorax was longitudinally opened, right atrium was incised and the heart was perfused with phosphatebuffered saline (PBS, $\mathrm{pH}=7.4$ ) through the apex of left ventricle. Heart was dissected out, rinsed with PBS, embedded in OCT compound (Jung, Nussloch, Germany) and snap frozen. Blocks were mounted on cryostat holders and $10-\mu \mathrm{m}$-thick sections were cut. Serial sections from the proximal $1 \mathrm{~mm}$ of the aortic root were collected on separate slides, air dried and fixed in acetone (immunohistochemistry) or in $4 \%$ phosphate-buffered paraformaldehyde (other stainings). Sections subjected to micro-XRF examination were mounted on 3.5- $\mu$ m-thick Mylar foil (Oxford Instruments, Espoo, Finland), freeze dried and left unfixed.

\subsection{Histological and immunohistochemical stainings}

Consecutive sections were stained to visualize specific components present in atherosclerotic plaques. Oil red-O (ORO) was applied to demonstrate lipids and indirect double immunofluorescence staining for CD68 and smooth muscle $\alpha$-actin (SMA) allowed simultaneous detection of macrophages and smooth muscle cells (Jawien et al., 2006). For immunohistochemistry, the sections were incubated overnight at room temperature in humid chambers with mixture of primary antibodies: Cy3-conjugated anti-SMA (Sigma Aldrich, St. Louis, MO, \#C6198; diluted 1:600) and rat anti-mouse CD68 (Serotec, Oxford, UK, \#MCA1957XZ; diluted 1:800). Then, goat anti-rat IgG biotinylated serum (diluted 1:800) was applied, followed by DTAF-conjugated streptavidin (diluted 1:500; both from Jackson IR, West Grove, PA). Finally, sections were mounted in glycerol-PBS $(\mathrm{pH}=8.6)$.

\subsection{Microscopic examination}

Histologically stained sections were examined in transmitted light under an Olympus BX50 microscope (Olympus, Tokyo, Japan). The same microscope equipped with mercuric burner and filter sets: U-MNG and U-MNIBA for detection of Cy3 (red) and DTAF (green) fluorescence, respectively, was used to examine immunofluorescence. Images of the aortic roots were recorded using Olympus DP71 digital CCD camera and stored as TIFF files. From sections stained for oil red$\mathrm{O}$, the total area of the lesion was measured semi-automatically in each slide using Olympus AnalySIS FIVE software (manually encircled areas were measured by the software). Areas occupied by macrophages (CD68-immunopositive) and by smooth muscle cells in neointima (SMA-immunopositive) were quantified in the same way. For each animal, a mean lesion area was calculated from eight sections reflecting the cross-sectional area covered by lipid deposits or occupied by intimal smooth muscle cells and macrophages.

\subsection{XRF setup and measurements}

All micro-XRF measurements were carried out at beamline $\mathrm{L}$ of the storage ring DORIS III at Hasylab (DESY, Hamburg, Germany). The experiment was conducted in the air. A sample was placed at $45^{\circ}$ angle to the beam axis. The primary photon energy was set to $17.5 \mathrm{keV}$ by a multilayer double monochromator. A polycapillary half-lens was used for beam focusing, hence the final beam size on the sample was approximately $15 \mu \mathrm{m}$ in diameter. X-ray emission was recorded with Vortex SSD semiconductor detector. Two types of recordings were performed on studied sections. Two-dimensional maps were acquired from lesional areas of the aortic root with neighboring cardiac muscle (resolution $15 \mu \mathrm{m}$, time of acquisition $3 \mathrm{~s}$ from each point). From histologically defined areas (atheromas), precise point spectra were recorded (resolution $15 \mu \mathrm{m}$, time of acquisition $300 \mathrm{~s}$ ). The obtained spectral data were processed and distribution maps were generated employing a non-linear least squares fitting strategy with the use of AXIL software, Linux version. The results (count numbers) were normalized to beam current, thickness of the sample and time, and expressed in arbitrary units. 


\subsection{Statistical analysis}

Differences in lesion areas stained histologically and in elemental concentrations between experimental groups were tested with Mann Whitney Wilcoxon U-test using Statgraphics 2.3 software (Manugistics, Bethesda, MD). $p$ Value less than 0.05 was considered statistically significant. Data were presented in the form of Tukey's 'box-and-whisker' plots showing median, lower and upper quartiles (box), the farthest data still within 1.5 times of the interquartile range (whiskers) and outliers (circles).

\section{Results}

\subsection{Histology}

As revealed by oil red-O staining, well developed atherosclerotic lesions were observed in all studied groups. More advanced atherosclerosis manifested by larger total area occupied by lipids was found in animals fed egg-rich diet (Figs. 1a, b and 2a). The perindopril treatment attenuated these effects (Figs. 1b, c and 2a). Total lesion area measured in the cross-sectioned aortic roots was $1,897,809 \pm$ $188,732 \mu \mathrm{m}^{2}$ in animals of LYOPH group and it was higher than that in CHOW group $\left(776,515 \pm 147,483 \mu \mathrm{m}^{2}, p<0.05\right)$. In comparison to LYOPH group, additional supplementation of the diet with perindopril (LYOPH/PERIND) resulted with inferior lesion area that was $876,182 \pm 86,860 \mu \mathrm{m}^{2}(p<0.05)$ reaching the level similar to chow diet-fed animals. Similar pattern was observed for areas occupied by CD68-immunopositive macrophages; however the decrease in macrophage-occupied area after pharmacological treatment was not statistically significant (Figs. 1d-f and 2b). No significant differences were observed in the number of intimal smooth muscle cells (Figs. 1d-f and 2c).

Two-dimensional mapping revealed distinct calcification foci in the atherosclerotic lesions (Fig. 1g-i).

\subsection{Elemental distributions}

In animals fed egg-rich diet, significantly higher concentrations of $\mathrm{Ca}$ and significantly lower contents of $\mathrm{S}, \mathrm{Cl}, \mathrm{Fe}, \mathrm{Cu}, \mathrm{Zn}$ and
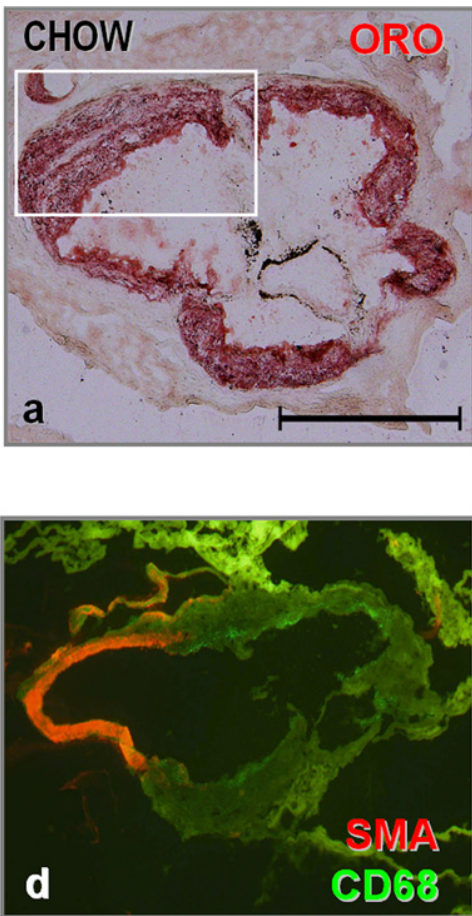
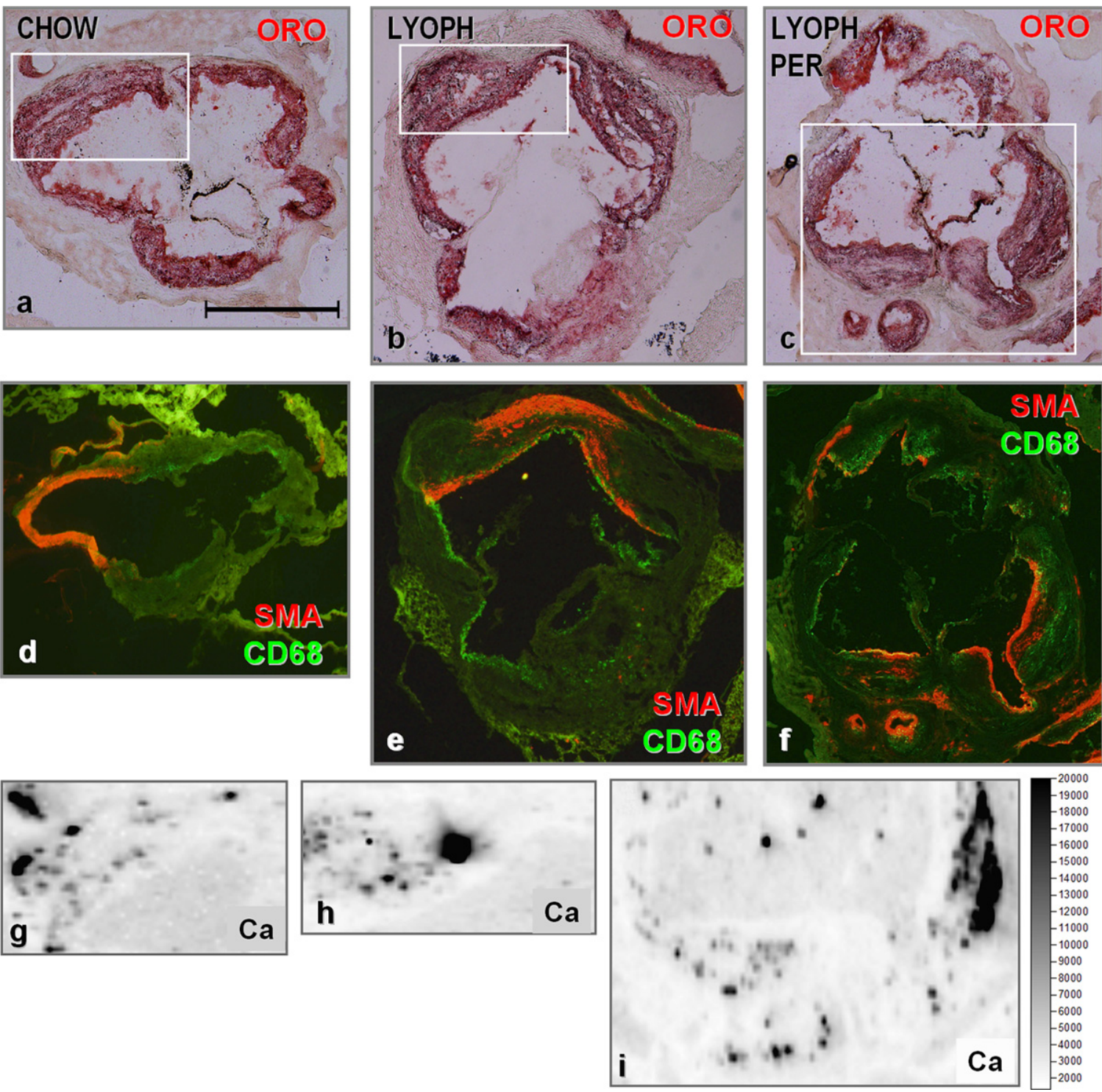

Fig. 1. Corresponding areas in consecutive sections of aortic roots of mice from groups CHOW (a, d, g), LYOPH (b, e, h) and LYOPH/PERIND (c, f, i). Panels a, b and c: oil red$\mathrm{O}$ staining for lipids; d, e and f: double immunostaining for smooth muscle actin (red) and CD68 (green); g, h and i: two-dimensional distribution of calcium in areas framed in a, b and c. Scale bar $=500 \mu \mathrm{m}$. Gray scale intensity bar shows number of counts for calcium. (For interpretation of the references to color in this figure legend, the reader is referred to the web version of this article.) 
Se in atheromas were seen in comparison to chow diet-fed animals. After perindopril treatment, concentrations of $\mathrm{S}, \mathrm{Cl}, \mathrm{Fe}$, $\mathrm{Cu}, \mathrm{Zn}$ and Se showed the tendency to achieve levels like in chow diet-fed animals. K level was similar in CHOW and LYOPH groups and significantly higher when compared to LYOPH/PERIND group. Concentrations of $\mathrm{P}$ did not vary significantly in all experimental groups. Relative contents (in arbitrary units) of the studied elements are presented in Fig. 3 and statistical significance of
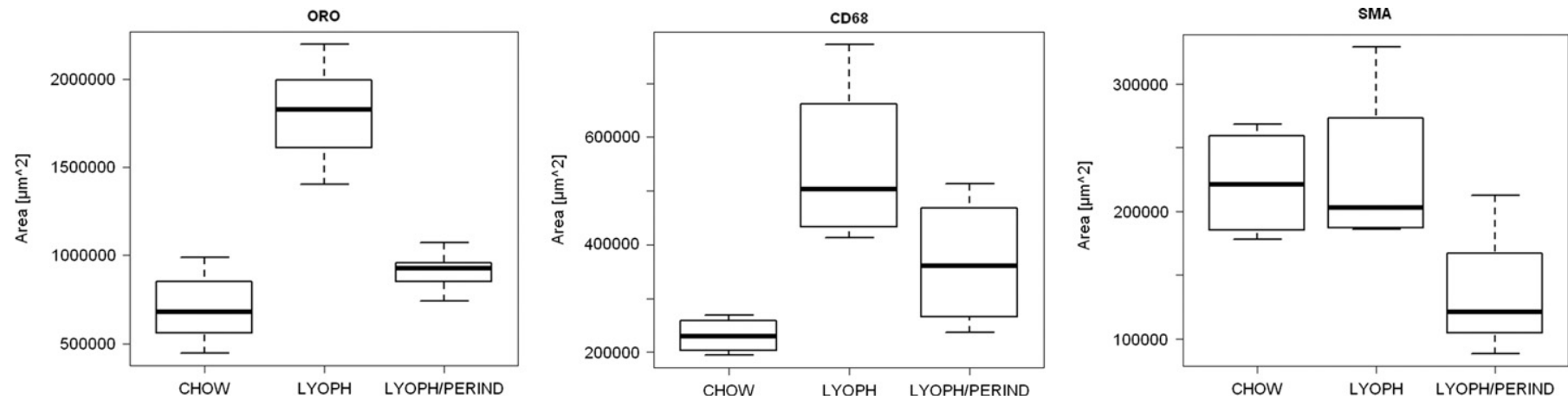

Fig. 2. Measured areas of lesions in aortic roots occupied by oil red-O stained lipids (total lesion area, ORO; a), macrophages (CD68; b) and smooth muscle cells (SMA; c).
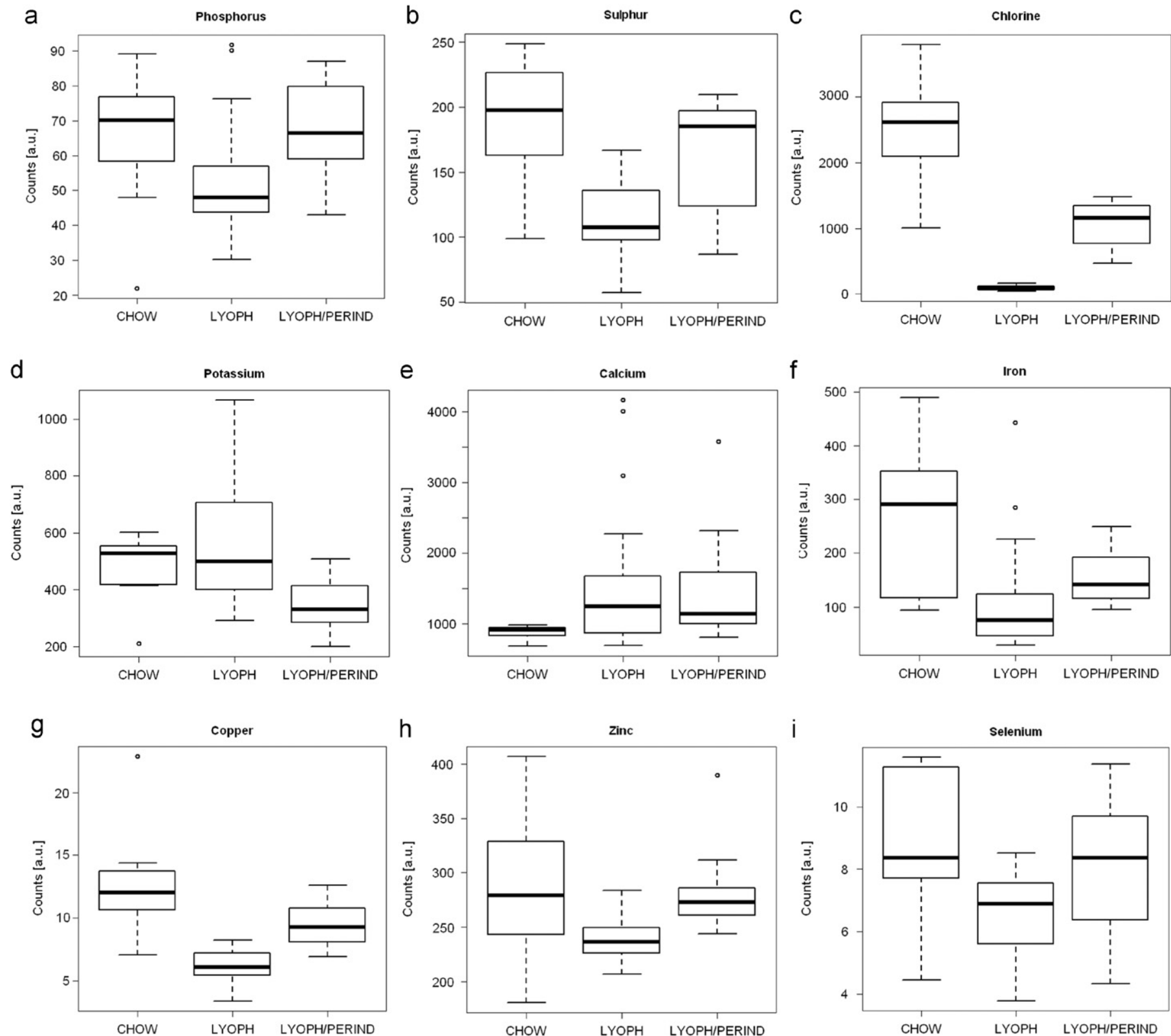

Fig. 3. Relative concentrations of phosphorus (a), sulfur (b), chlorine (c), potassium (d), calcium (e), iron (f), copper (g) zinc (h) and selenium (i) in atheromas of studied mice. 
Table 1

Comparison of morphological parameters and elemental concentrations between experimental groups (Mann Whitney U-test - one-tailed, $p$ values).

\begin{tabular}{lclc}
\hline & CHOW vs. LYOPH & $\begin{array}{l}\text { CHOW vs. } \\
\text { LYOPH/PERIND }\end{array}$ & $\begin{array}{l}\text { LYOPH vs. } \\
\text { LYOPH/PERIND }\end{array}$ \\
\hline ORO & $<\mathbf{0 . 0 0 1}$ & $\mathbf{0 . 0 1 8}$ & $<\mathbf{0 . 0 0 1}$ \\
CD68 & $\mathbf{0 . 0 1 5}$ & 0.056 & 0.096 \\
SMA & 0.44 & 0.056 & 0.056 \\
P & 0.082 & 0.42 & 0.18 \\
S & $\mathbf{0 . 0 0 2}$ & 0.13 & $<\mathbf{0 . 0 0 1}$ \\
Cl & $<\mathbf{0 . 0 0 1}$ & $\mathbf{0 . 0 0 2}$ & $<\mathbf{0 . 0 0 1}$ \\
K & 0.26 & $\mathbf{0 . 0 1 1}$ & $<.001$ \\
Ca & $\mathbf{0 . 0 3 2}$ & $\mathbf{0 . 0 0 5}$ & 0.44 \\
Fe & $\mathbf{0 . 0 0 9}$ & 0.14 & $\mathbf{0 . 0 1 2}$ \\
Cu & $<\mathbf{0 . 0 0 1}$ & $\mathbf{0 . 0 2 4}$ & $<\mathbf{0 . 0 0 1}$ \\
Zn & $\mathbf{0 . 0 3 6}$ & 0.48 & $\mathbf{0 . 0 1 4}$ \\
Se & $\mathbf{0 . 0 1 1}$ & 0.21 & \\
\hline
\end{tabular}

differences (in histological parameters and elemental concentrations) between the studied groups is shown in Table 1.

\section{Discussion}

This study presents the effects of ACE inhibitor perindopril on histological composition and elemental content of atheromas in apoE/LDLR ${ }^{-1-}$ mice subjected to proatherogenic egg-rich diet. As assessed histologically, the diet considerably potentiated atherosclerosis. Similar effect was also observed in mice (Franczyk-Zarow et al., 2008) and in other vertebrate species (Garcia et al., 2003; Wong and Chan, 1980). Perindopril showed its efficacy to reduce development of atherosclerosis, as estimated by the size of atheroma. In apoE-knockout mice, perindopril and enalapril decreased the size of lipid core by $52.9 \%$ and $38.98 \%$, respectively, and reduced number of macrophages by $88.38 \%$ and $52.16 \%$, respectively (Lu et al., 2008). Furthermore, perindopril inhibited the development of atherosclerotic lesions in diabetic (streptozotocin-induced) apoE-knockout mice (Candido et al., 2002). ACE inhibitors are known of their antiinflammatory properties. Reduced number of macrophages observed in our study may reflect lower recruitment of inflammatory cells to the affected vessel. Moreover, we demonstrated reduced atherosclerosis after perindopril administration in animals fed highly proatherogenic diet.

Among the elements examined in this study, only calcium showed behavior corresponding with the advancement of atherosclerotic lesions in the treated mice (increase after egg-rich diet and decrease - albeit insignificant - after perindopril treatment). The other elements (except from potassium) revealed the opposite pattern (decrease/increase), mostly showing statistical significance of differences. This is an interesting finding, which suggests that advancement of atherosclerotic lesion is somehow associated with depletion of most elements studied from the lesion, while regression of the lesion brings the elements back. Such effect could be expected in case of elements with antiatherogenic properties; however, in our study it also concerned with some proatherogenic elements.

Calcification is common in advanced atherosclerotic lesions. In this study, higher content of calcium in atheromas was observed in animals fed egg-rich diet, and the two-dimensional maps of the lesions showed distinct calcification foci. Higher concentration of calcium in atheromas (intima) than in vascular media was also found in aortic roots of apoE/LDLR ${ }^{-1-}$ mice (Gajda et al., 2008). Calcification of advanced atherosclerotic lesions in innominate arteries of apoE-knockout mice was reported by Rattazzi et al. (2005). The process was preceded by changes in extracellular matrix, appearance of chondrocyte-like cells and finally deposition of calcium phosphate crystals. Surprisingly, in our study we did not observe the corresponding significant increase in the content of phosphorus within atherosclerotic lesions after feeding animals with proatherogenic diet. This may be explained by the presence of calcium deposit forms other than phosphates (e.g. hydroxyapatite), such as carbonates or lactates (Rokita et al., 1991).

Iron was shown to promote atherosclerosis mostly by its ability to oxidize LDLs (Heinecke, 1998). In rabbits, iron chelator (desferrioxamine) inhibited development of atherosclerosis and lowered iron concentration in atherosclerotic plaques (Minqin et al., 2005). In our studies, iron content was lower in egg-rich diet-fed animals and its concentration increased after perindopril treatment, suggesting that irrespective of its antiatherogenic effect, perindopril promoted accumulation of that proatherogenic element in the atheroma. In carotid arteries of apoE-knockout mice, decrease in concentration of iron was observed in media (either with or without overlying lesion) of probucol (lipid soluble antioxidant reducing atherosclerosis) treated animals (Minqin et al., 2007). This discrepancy might arise from different animal models used in our study (apoE/LDL-double knockout vs. apoE-knockout mice) and from different areas of vascular wall examined: we analyzed iron concentration in lesions (neointima) of aortic roots, in contrast to media of carotid arteries studied by Minqin and coworkers.

Zinc supplementation has been shown to exert an antiatherogenic effect. Zinc is a cofactor of superoxide dismutase, an enzyme involved in free radical breakdown and it is also present in matrix metalloproteinases, the enzymes responsible for remodeling of extracellular matrix components. Rabbits fed a high-cholesterol diet supplemented with zinc displayed milder atherosclerosis than animals treated without zinc supplementation (Ren et al., 2006). In probucol treated apoE-knockout mice, higher zinc concentration, as well as higher $\mathrm{Zn} / \mathrm{Fe}$ ratio, was observed in carotid arteries as compared to control animals (Minqin et al., 2007). Atherosclerotic lesion formation may be accelerated by free radical yielding caused by elevated iron levels and zinc was supposed to antagonize such effect (Minqin et al., 2003). In our study we observed, accordingly, lower zinc concentration in atheromas of animals fed proatherogenic diet and increase in its content after pharmacotherapy.

Cupric ions were shown to induce formation of lipid peroxides and thus promoting atherosclerosis (Lynch and Frei, 1995). On the other hand, copper is a component of free radical-scavenging $\mathrm{Cu}-\mathrm{Zn}$ superoxide dismutase. In the present study, copper was significantly lower in mice fed proatherogenic diet and administration of perindopril increased its level. Very low concentration of copper in atheromas may suggest that in spite of its potential proatherogenic activity, it plays a minor role in promotion of atherosclerosis (Rajendran et al., 2007).

Sulfur is present in most proteins as a component of methionine and cysteine. In atherosclerotic lesions, however, its main bulk is associated with matrix proteoglycans containing sulfated glycosaminoglycans. Lower concentration of sulfur in atheromas of mice fed egg-rich diet may reflect remodeling of extracellular matrix components (Katsuda and Kaji, 2003).

Potassium was the only element to deviate from the observed pattern. It is a common intracellular ion, being a typical component and marker of cell-rich areas and as such it is less likely to influence atherosclerosis development.

\section{Conclusion}

In our study we showed beneficial effects of ACE inhibitor perindopril on the development of atherosclerosis intensified by 
high-cholesterol diet in an atherogenesis-prone animal model. Perindopril decreased the extent of atherosclerotic lesion in terms of lesion area; moreover, it retained the concentration of pro- and antiatherogenic elements in atheromas at the level observed in animals fed a standard diet. Further clinical studies are required to prove the value of ACE inhibitors in the prevention of cardiovascular disorders.

\section{Acknowledgments}

Financial support was provided by statutory Grant K/ZDS/ 000685 from Jagiellonian University Medical College to M.G. The study was supported by contract RII3-CT-2004-506008 (IA-SFS) of the EU Commission. The data were obtained during realization of DESY-D-I-20090125 EC and II-20100089 EC projects.

\section{References}

Candido, R., Jandeleit-Dahm, K.A., Cao, Z., Nesteroff, S.P., Burns, W.C., Twigg, S.M., Dilley, R.J., Cooper, M.E., Allen, T.J., 2002. Prevention of accelerated atherosclerosis by angiotensin-converting enzyme inhibition in diabetic apolipoprotein E-deficient mice. Circulation 106, 246-253.

Ceconi, C., Fox, K.M., Remme, W.J., Simoons, M.L., Deckers, J.W., Bertrand, M., Parrinello, G., Kluft, C., Blann, A., Cokkinos, D., Ferrari, R., 2009. ACE inhibition with perindopril and biomarkers of atherosclerosis and thrombosis: results from the PERTINENT study. Atherosclerosis 204, 273-275.

Constant, J., 2004. The role of eggs, margarines and fish oils in the nutritional management of coronary artery disease and strokes. Keio J. Med. 53, 131-136.

Franczyk-Zarow, M., Kostogrys, R.B., Szymczyk, B., Jawien, J., Gajda, M., Cichocki, T., Wojnar, L., Chlopicki, S., Pisulewski, P.M., 2008. Functional effects of eggs, naturally enriched with conjugated linoleic acid, on the blood lipid profile, development of atherosclerosis and composition of atherosclerotic plaque in apolipoprotein $\mathrm{E}$ and low-density lipoprotein receptor double-knockout mice (apoE/LDLR ${ }^{-1-}$ ). Br. J. Nutr. 99, 49-58.

Gajda, M., Banas, K., Banas, A., Jawien, J., Mateuszuk, L., Chlopicki, S., Kwiatek, W.M., Cichocki, T., Falkenberg, G., 2008. Distribution of selected elements in atherosclerotic plaques of apoE/LDLR-double knockout mice assessed by synchrotron radiation-induced micro-XRF spectrometry. X-Ray Spectrom. 37, 495-502.

Garcia, P.B., Ayala, I., Castells, M.T., Madrid, J.F., Ortega, M.R., Ortega, J.V., Ballesta, J., Fernandez, P.J., Valdes, M., 2003. Planimetric and histological study of the aortae in atherosclerotic chickens treated with nifedipine, verapamil and diltiazem. Histol. Histopathol. 18, 1027-1033.

Hansson, G.K., 2005. Inflammation, atherosclerosis, and coronary artery disease. N. Engl. J. Med. 352, 1685-1695.

Heinecke, J.W., 1998. Oxidants and antioxidants in the pathogenesis of atherosclerosis: implications for the oxidized low density lipoprotein hypothesis. Atherosclerosis $141,1-15$.

Jawien, J., Gajda, M., Rudling, M., Mateuszuk, L., Olszanecki, R., Guzik, T.J., Cichocki, T., Chlopicki, S., Korbut, R., 2006. Inhibition of five lipoxygenase activating protein (FLAP) by MK-886 decreases atherosclerosis in apoE/LDLR-double knockout mice. Eur. J. Clin. Invest. 36, 141-146.

Katsuda, S., Kaji, T., 2003. Atherosclerosis and extracellular matrix. J. Atheroscler. Thromb. 10, 267-274.

Lu, Q., Ke, Y.N., Cheng, W.L., Wang, Y., Yu, C.A., Wen, J.Y., 2008. Effects of perindopril and enalapril on atherosclerosis development of apolipoprotein $\mathrm{E}$ knockout mice. Zhonghua Xin. Xue. Guan. Bing. Za Zhi. 36, 350-354.

Lynch, S.M., Frei, B., 1995. Reduction of copper, but not iron, by human low density lipoprotein (LDL). Implications for metal ion-dependent oxidative modification of LDL. J. Biol. Chem. 270, 5158-5163.

McNamara, D.J., 2000. Dietary cholesterol and atherosclerosis. Biochim. Biophys. Acta 1529, 310-320.

Minqin, R., Watt, F., Huat, B.T., Halliwell, B., 2003. Correlation of iron and zinc levels with lesion depth in newly formed atherosclerotic lesions. Free Radic. Biol. Med. 34, 746-752.

Minqin, R., Rajendran, R., Pan, N., Tan, B.K., Ong, W.Y., Watt, F., Halliwell, B., 2005. The iron chelator desferrioxamine inhibits atherosclerotic lesion development and decreases lesion iron concentrations in the cholesterol-fed rabbit. Free Radic. Biol. Med. 38, 1206-1211.

Minqin, R., En, H., Beck, K., Rajendran, R., Wu, B.J., Halliwell, B., Watt, F., Stocker., R., 2007. Nuclear microprobe investigation into the trace elemental contents of carotid artery walls of apolipoprotein E deficient mice. Nucl. Instrum. Meth. B. 260, 240-244.

Rajendran, R., Ren, M., Ning, P., Tan Kwong, H.B., Halliwell, B., Watt, F., 2007. Promotion of atherogenesis by copper or iron - which is more likely? Biochem. Biophys. Res. Commun. 353, 6-10.

Rattazzi, M., Bennett, B.J., Bea, F., Kirk, E.A., Ricks, J.L., Speer, M., Schwartz, S.M., Giachelli, C.M., Rosenfeld, M.E., 2005. Calcification of advanced atherosclerotic lesions in the innominate arteries of ApoE-deficient mice: potential role of chondrocyte-like cells. Arterioscler. Thromb. Vasc. Biol. 25, 1420-1425.

Ren, M., Rajendran, R., Ning, P., Tan Kwong, H.B., Choon, N.O., Watt, F., Jenner, A., Halliwell, B., 2006. Zinc supplementation decreases the development of atherosclerosis in rabbits. Free Radic. Biol. Med. 41, 222-225.

Rokita, E., Cichocki, T., Heck, D., Jarczyk, L., Strzalkowski, A., 1991. Calcification of aortic wall in cholesterol-fed rabbits. Atherosclerosis 87, 183-193.

Wong, H.Y., Chan, S.W., 1980. The effects of egg yolk diet on serum lipids, aortic atherosclerosis and connective tissue in male miniature pigs. Artery 7, 32-43. 